\title{
Need for Containment as a Motivation for Facebook Use
}

\author{
Liat Feldman \\ University of Haifa, Haifa, Israel \\ Email: liat@liatfeldman.com
}

How to cite this paper: Feldman, L. (2018) Need for Containment as a Motivation for Facebook Use. Social Networking, 7, 1-18. https://doi.org/10.4236/sn.2018.71001

Received: July 18, 2017

Accepted: November 14, 2017

Published: November 17, 2017

Copyright $\odot 2018$ by author and Scientific Research Publishing Inc. This work is licensed under the Creative Commons Attribution International License (CC BY 4.0).

http://creativecommons.org/licenses/by/4.0/

\begin{abstract}
Research reveals a mixed picture regarding Facebook uses and psychological effects associated with them. This study looks at this issue through the lens of the psychoanalytic concept of containment. We combined this concept with the anxious and avoidant forms of attachment to create a framework with which to investigate the active and passive uses of Facebook. Using a questionnaire administered to 275 Israeli students, we established that the need for containment predicted logging onto and posting on Facebook after negative experiences. In addition, fulfillment of one's need for containment was associated with posting on Facebook. We also observed a positive change in one's feelings about oneself and one's subjective sense of visibility after posting on Facebook. These results offer a new approach to exploring both Facebook use and its effects.
\end{abstract}

\section{Keywords}

Facebook, Containment, Attachment Style, Psychological Effects, Online, Social Network

As Facebook maintains its status as the dominant social network with two billion users [1], the body of research examining the motivations for using Facebook and the possible effects of this use grows accordingly [2]-[7]. Along with findings emphasizing social gratifications such as re-connecting with former friends, networking, and inter-personal communication as motivations for using Facebook [8] [9] [10], studies have focused on the psychological motivations of self-formation and identity performance needs [4] [6] [11] [12]. Research examining the possible psychological effects of using Facebook reveals a mixed picture. While earlier findings supported a positive relationship between Facebook usage and users' wellbeing, social capital and sense of belongingness [13] 
[14] [15], most recent findings associate Facebook use with negative psychological effects such as depression, loneliness, anxiety, envy and concerns about one's body image [16] [17] [18] [19] [20]. Although most recent studies point out the negative psychological effects associated with Facebook use, some have documented its positive effects with more segmented populations such as reducing stress among women [21] [22] and the mentally ill [23].

We consider another psychological concept-containment-that may serve as a prism through which to examine the underlying motivation for using Facebook. It may also explain the mixed findings about the positive and negative psychological effects of using Facebook.

\section{Literature Review}

\subsection{Psychological Containment}

Containment is a concept in psychoanalytical object-relation theories that refers to certain dynamics of primal, non-verbal communication between a mother figure and an infant. This dynamic process is central to the development of internalization capabilities, leading to the formation of the "self" [24]. When referring to adults, containment ability is the capacity process, incorporate and relate to experiences, feelings and emotional impressions within the framework of one's self [25].

Human infants begin their psychological development with no clear, differentiated boundaries between the self and the outside world, between internal and external experiences. Threatening internal experiences may be projected outside, thus enabling the removal of these threatening parts from within the self into the outer world. These elements might be undefined sensations of hunger, fear, frustration and discomfort that might manifest themselves in crying, restlessness and fits of rage. The mother's ability to endure these "attacks" and meet the need they represent, rather than denying them or being overwhelmed by them, is a work of containment. Thus, the mother figure serves as a container, a metaphorical holding vessel for processing these projected elements. Emotional functions of containment performed by the mother include mirroring and echoing when she identifies the infant's needs in terms such as "you're cold" or "you're hungry". She may also engage in metaphorical holding that allows the infant to suspend recognition of his/her own helplessness [26]. Identifying the need behind an infant's crying and responding to it appropriately, for example, by holding, feeding or nursing the child to sleep, is a form of emotional processing performed by the mother. This processing enables the infant to incorporate these transformed and now less threatening elements back into its forming self, thus learning to identify his/her needs, fears, longings and emotions within his or her self [27]. Retrieving once projected elements back as part of the self is the foundation of identity formation and the capacity for self-containment, enabling the self to grow and develop [28]. These processes, initiating in early stages of life, are the basis of the human ability to communicate, form relationships, and devel- 
op a sense of self-esteem [29] [30]. The internalization processes and dynamics of containment that are central to the development of the self-serve as a blueprint for the ability to self-contain, the ability to bear, withhold and process the internal and external experiences of adult life. The climate and quality of early containment experiences are central in establishing one's level of containment needs, meaning the need for others to process meaningful positive and negative life experiences.

The emotional arena in which early containment dynamics takes place was conceptualized as a potential space by Donald Winnicott [26]. He defined this space as a metaphorical matrix in which psychological holding is enabled and exercised, allowing the maturation and growth of the infant's self, secured in a symbolic safety net. We investigate the possibility that Facebook serves as a potential space in which people can fulfill their need for containment.

Facebook as a platform for examining containment needs and their fulfillment. As a digital social network, Facebook provides an accessible, virtual space for communicating, sharing and responding to others. Previous studies established the desire for belongingness as a motivation for using Facebook, defining it as the need for intimacy, closeness, friendship and sharing [4] [11]. Facebook emphasizes sharing among its members because it is a vital component of social networks. The virtual space in which Facebook operates is a realm not confined by time, space, or geography. It contains elements of reality and fantasy, which enables play and practice in identity, self-expression and self-formation [12]. Sunden [31] noted that metaphorically, "We write ourselves into being" when writing on a virtual social network site. Similarly, Turkle [32] stated that the screen itself could be perceived as a symbolic mirror in which parts of the user's self are reflected.

These descriptions resonate in many ways with the concept of potential space, apart from the crucial element of unconditional love associated with motherinfant relationship. Sharing one's status, a photograph, or a comment are all ways of sharing parts of the self on Facebook. Regardless of its content and nature, each response to a "self" element shared on Facebook is a validation of one's existence, an admission of recognition by others. Responses may serve as mirroring and echoing, which are functions of containment. Facebook's connectedness, which enables constant communication with others, might suggest that one is never alone. Can Facebook serve as an arena in which people can express their containment needs? Can these needs be fulfilled in this arena? Using the lens of containment to investigate these questions raises both theoretical and methodological challenges. The concept of containment was developed in the framework of psychoanalytic therapy. It has not been defined in an operational manner. To meet that dual challenge, we bring together the concept of containment and adult attachment theory [33].

\subsection{Adult Attachment Theory}

Adult attachment theory derives from Bowlby's attachment theory, in which early childhood experiences with major caregivers shape one's relationships in 
adult life [33] [34]. When emotional needs such as comfort, holding and security are fulfilled by a caregiver, usually the mother, a secure attachment base can develop. A secured attachment base allows oneself to feel worthy of love, and to perceive others as trustworthy [35]. An inconsistent fulfillment of the infant's psychological and physical needs might result in an insecure attachment base that can be characterized as anxious or avoidant. In an anxious attachment model, fear of being abandoned and an anticipated rejection by others color relationships with an anxious tone [36]. Adults characterized with an anxious attachment style demonstrate a pre-occupation with the responses of significant others and a heightened awareness of the signs of possible abandonment by significant others. They invest energy in preserving their self-presentation and enhancing existing relationships, while seeking affirmation by and proximity to significant others [35] [36]. In contrast, a consistent experience of neglect of one's emotional and other needs might lead to an avoidant attachment style, in which others are perceived as untrustworthy or undependable, and the self as autonomous and self-sufficient [36]. Adults with an avoidant attachment style seem to be emotionally numb, avoiding closeness and suppressing their needs from significant others to avoid disappointment. They are reluctant to reveal themselves to others and try to satisfy their emotional needs on their own.

Adult attachment theory and containment. Mother-infant dynamics in which mother figure is emotionally and physically tuned to the infant was referred in attachment theory as envelope interaction, a metaphor for the way mother and infant are entwined in meeting infant's needs and in establishing a secure psychological reality for them [29]. Envelope interaction, which is the core of attachment base forming has been equated with the dynamics of containment [37]. This analogy paves the way for us to integrate attachment theory and the concept of containment theoretically.

Attachment styles can be described in terms of containment needs. Adults with a secure attachment style have enjoyed an emotional environment of satisfactory containment. Thus, they experience themselves as valuable, and can develop trust and confidence in themselves and others, relieved of fears of extreme dependency or abandonment. They can balance internal processing with communication with others to process various experiences. However, when containment needs are not fulfilled, they compromise the development of a secure attachment base. Adults with an anxious attachment style had their containment needs met in a partial or inconsistent manner. Thus, their sense of security is fragile and depends on physical and emotional proximity and the mirroring of a significant other. An inconsistent emotional presence of a mother figure has prevented the sound internalization of the projected elements of the self, resulting in a strong need for others to regulate and process the individual's emotional experiences, as well as for self-affirmation. Adults with an avoidant attachment style have had their containment needs consistently ignored. This does not mean that their containment needs are low. Rather they have learned to satisfy their 
own needs and mute their expression of these needs. Attachment style in research today is viewed alongside two dimensions-anxious and avoidant [38]. A secured attachment style manifests in a low score in both anxious and avoidant dimensions, where an avoidant attachment style manifests in a high score in avoidant dimension and a low score in anxiety dimension [39].

While the concept of containment resides in the theoretical thinking of psychoanalytical treatment, original attachment theory and adult attachment theory are well established in the field of research. Since attachment theory is centered on internalized relations with others, the social network is a fertile ground for examination of differences in Facebook use and motivations among users with different attachment styles.

Attachment style and Facebook use. Oldmeadow and colleagues [36] found a positive correlation between an anxious attachment style and Facebook use. In their study, subjects with an anxious attachment style spent more time using Facebook and expressed more concerns about the responses of others to them than those with a different attachment style. These subjects also tended to use Facebook more when they were worried or overcome by negative feelings such as loneliness, stress or boredom. These findings were supported in a later study [39]. Given that fulfilling basic containment needs is a central part of shaping one's attachment style, these findings may support this study's general hypotheses that Facebook use is correlated with one's level of containment needs. Adults presenting an anxious attachment style have not enjoyed a consistent and satisfactory fulfillment of their containment needs. Thus, the process of establishing one's self as a stable, whole entity rather than a fragmented being has not been realized. For such people, the approval of others is crucial for validating one's self. The search for such approval is evident in how they use Facebook.

To examine the possible relationship between Facebook use and containment needs, we also include several parameters that have not been considered in previous studies. The speed of connecting to and posting on Facebook after the occurrence of a negative event is a parameter associated with containment needs. We expect that those with strong containment needs will log onto a social network faster than others after the occurrence of a meaningful event, because the presence of others, even symbolically, is crucial for the processing of emotional experiences. Other factors we will consider are the frequency and duration of using Facebook and a categorization of that use as active or passive. Examples of active and passive include whether one writes on Facebook or post pictures as opposed to just reading the posts of others.

\subsection{Hypotheses}

The theoretical link between containment needs and attachment style [40] has never been tested, and would be the first area of investigation in this present study. Based on the literature reviewed above, we posit that:

H1a: A positive relationship will be found between the anxious attachment 
style and the need for containment.

H1b: A negative relationship will be found between the avoidant attachment style and the need for containment.

Given that containment dynamics are linked to the processing of negative and threatening experiences [27] we expect that:

H2: A positive relationship will be found between containment needs and the anxiety dimension of attachment style and the sharing of negative experiences on Facebook.

We also add two new parameters of Facebook use-the speed of connecting and sharing on Facebook after the occurrence of a negative experience-to this hypothesis. Thus, we posit that:

H3: A positive relationship will be found between containment needs, the fulfillment of these needs, the anxiety dimension of attachment style and the speed of logging onto Facebook after the occurrence of a negative experience.

We also expect that:

H4: A positive relation will be found between containment needs, fulfillment of these needs, the anxiety dimension of attachment style and the speed of posting on Facebook after the occurrence of a negative experience (H4).

The next hypotheses deal with the effects of having one's containment needs met and the experience of the self.

H5: A positive relation will be found between an experience of containment, the anxiety dimension of attachment style and the perception of a positive change in feeling when using Facebook.

H6: A positive relation will be found between an experience of containment, the anxiety dimension of attachment style and the feeling of the "self" being seen (self-visibility) on Facebook.

\section{Method}

\subsection{Participants and Process}

A cross sectional design survey was administered throughout 2014 to 275 Israeli students from various universities across the country. The participants had an average age of 28 years $(\mathrm{SD}=8)$ and were mostly female $(71 \%)$. The 85 -item questionnaire included a short version of the ECR-i, an attachment questionnaire [38], and items about the participants' behavior on and use of Facebook such as reading and writing posts, the nature of the material they post on Facebook, the changes in feeling they experienced after sharing posts on Facebook, and items assessing their containment needs. The participants indicated the degree to which they agreed with the statements on a 7-point Likert scale ranging from 1, signifying "never", to 7 , meaning "always", we determined the items to include in the final version of the survey after two preliminary studies.

\subsection{Measurements}

The containment needs questionnaire. The concept of containment refers to 
the dynamics of communication that are non-verbal and unconscious. However, the footprints of these early development processes are evident in the ability of adults to process internal and external experiences. This study deals with the elements of containment needs and their fulfillment about which people can be introspective and report to others. A central element of containment needs is the craving to communicate and share one's external and internal experiences with others to process them emotionally. Thus, this study regards the need for containment as a need for emotional sharing. Some of the items in the questionnaire address sharing behaviors and needs. Examples include: "When something good happens to me, I feel the need to share it with others"; "When something bad happens to me, I feel a need to share it with others" and "I tend to share day to day experiences with others". Among those with a stronger need for containment, the inability to share with others might evoke feelings of stress, anxiety and tension. We assessed that possibility with the statement: "When I cannot share my feeling and experiences with others, I feel stressed or anxious." The fulfillment of one's containment needs prompts feelings of relief, of being visible and of being validated. Sample items measuring this possibility include: "After sharing with others, I feel better" and "When sharing with others, I feel I am seen".

The preliminary version of the containment questionnaire included 21 items and was administered to 50 Israeli university students from Haifa and Tel Aviv, 42 of whom answered the questionnaire completely. This questionnaire achieved an internal reliability of $\alpha=0.88$, but a principal component analysis and Varimax rotation revealed six different components. Perhaps these results were due to the relatively small sample size, but it was clear that further work needed to be done to create a more coherent questionnaire.

In a second pilot, we administered a new questionnaire to 60 Israeli students. We eliminated the items in the first questionnaire that had high internal correlations. For example, we found no differences between items related to one's family and those related to one's friends, so we combined them. Items regarding non-sharing behavior mirrored those about sharing behavior and were omitted. We added an item regarding the transformative nature of the containment process to measure how the responses of others help the processing of emotion: "When I share a negative experience or feeling I have with others, the experience or feeling seem less negative than before." The second version of the containment questionnaire included 12 items and achieved an internal reliability of $\alpha=$ 0.89. Component analysis in Varimax rotation with Keizer normalization suggested three components: sharing behavior $(\alpha=0.795)$, the need for sharing ( $\alpha=$ $0.865)$ and the effect of sharing $(\alpha=0.816)$. Some items loaded on more than one component that fit the three content worlds suggested in those components. For example, item number 8 ("Sharing helps me feel better about myself") deals with the effects of sharing and with sharing behavior. A component analysis revealed that the three components reduced to two, explaining $66.08 \%$ of the va- 
riance-the need to share or the containment need and the effect of sharing, the experience of being contained, and the fulfillment of containment needs. Eight items included in this component loaded between 0.60 and 0.84 and explained $37.99 \%$ of the variance, with a reliability of 0.87 . The effect of sharing included four items that loaded between 0.78 and 0.85 and explained $27.08 \%$ of the variance with a reliability of 0.90 . Table 1 illustrates the results. Expressions of the need for containment and the fulfillment of containment needs on Facebook could be found outside the exclusive containment questionnaire. Examples include items such as the content of what is shared ("I tend to share negative experiences and events on Facebook"), the speed with which the participants logon to Facebook after a meaningful negative or positive event, the change in one's feelings after sharing and the change in one's sense of self after sharing ("When I share personal experiences on Facebook, I feel less lonely" and "When I share personal experiences on Facebook, I feel understood"). These questions were

Table 1. Factor distribution in final containment questionnaire.

\begin{tabular}{|c|c|c|c|}
\hline \multirow{2}{*}{ No. } & \multirow{2}{*}{ Item } & \multicolumn{2}{|c|}{ Factor } \\
\hline & & 1 & 2 \\
\hline 1 & $\begin{array}{l}\text { I usually share negative events (e.g. a dispute at work, failure at } \\
\text { school, romantic disappointment, sad movie) or negative feelings } \\
\text { (sadness, frustration, anxiety, discomfort) in my life with others. }\end{array}$ & & 0.821 \\
\hline 2 & $\begin{array}{l}\text { I usually share positive events (e.g. success at school, a promotion, } \\
\text { joyous romantic occasion, enjoyable movie) or positive feelings } \\
\text { (happiness, pride, excitement) in my life with others. }\end{array}$ & & 0.850 \\
\hline 3 & $\begin{array}{l}\text { I feel the need to share negative events and feelings in my life with } \\
\text { others. }\end{array}$ & 0.417 & 0.744 \\
\hline 4 & $\begin{array}{l}\text { I feel the need to share positive events and feelings in my life with } \\
\text { others. }\end{array}$ & & 0.782 \\
\hline 5 & $\begin{array}{l}\text { When I'm sharing negative events and feelings I've experienced with } \\
\text { a close friend or an acquaintance, I feel better. }\end{array}$ & 0.700 & \\
\hline 6 & When I'm down, merely being with others makes me feel better. & 0.747 & \\
\hline 7 & $\begin{array}{l}\text { Sharing events and/or feelings I've experienced with others makes } \\
\text { me feel relieved. }\end{array}$ & 0.830 & \\
\hline 8 & $\begin{array}{l}\text { Sharing events and/or feelings I've experienced with others makes } \\
\text { me feel better about myself. }\end{array}$ & 0.739 & \\
\hline 9 & $\begin{array}{l}\text { When I can't share an experience, event or feeling with someone, I } \\
\text { feel anxiety or a certain kind of stress. }\end{array}$ & 0.676 & \\
\hline 10 & $\begin{array}{l}\text { When I experience a negative event or feeling, I share it the first } \\
\text { chance I get. }\end{array}$ & 0.685 & \\
\hline 11 & $\begin{array}{l}\text { When I experience a positive event or feeling, I share it the first } \\
\text { chance I get. }\end{array}$ & 0.608 & \\
\hline 12 & $\begin{array}{l}\text { When I share a negative experience or feeling I've experienced, the } \\
\text { event or feeling seem less negative than how I felt it was. }\end{array}$ & 0.783 & \\
\hline & $\mathrm{N}=275$ & $\alpha=0.896$ & $\alpha=0.868$ \\
\hline
\end{tabular}

${ }^{\star}$ Rotated component matrix model. 
included in the general survey.

Behavior and uses of Facebook. Thirty items were devoted to different behaviors on and uses of Facebook. The first 11 items dealt with habits of logging onto Facebook, such as its frequency and duration, and the speed of logging on and posting on Facebook after an internal or real event. Nineteen other items dealt with the active use of Facebook such as writing, regardless of whether about happy or sad events, posting a photograph, and using the "like" function, and the passive use evident in reading the posts and comments of others.

Change in reported feeling after using Facebook. The participants were asked to report if and how their feelings changed for the better or worse during various activities on Facebook such as after posting a personal status, after reading the posts of others or looking at their photographs, and reading comments about their posts. Their responses were recorded on a 7-point Likert scale in which 1 signified "my feeling worsens a great deal", 7 signified "my feeling improves immensely" and 4 signified "I don't experience any change in feeling". In order to check the factorial structure in the items related to changes in feeling, we conducted a principal components factorial analysis that revealed two factors that explained $65.84 \%$ of the general variance (eigenvalue $>1$ ): a positive change in feeling ( 7 items) and a negative change ( 2 items related to negative responses and no responses at all to posts).

The experience of the self and one's visibility on Facebook. We included several items to measure how the participants experienced themselves while using Facebook. Examples include: "When I'm on Facebook, I feel less lonely"; "When I'm on Facebook, I feel I'm being seen by someone" and "When I'm on Facebook, I feel I can express myself".

Attachment style questionnaire-ECR. The final version of the questionnaire included 16 items from the short version of the ECR [38]. We omitted two of the statements from the original short version after two preliminary studies showed that doing so would not compromise the reliability of the factor structure.

\section{Results}

We first investigated the relationship between containment needs and attachment style before we analyzed the relationship between these two factors and Facebook use. Correlations between two components of containment (need and fulfillment) and two dimensions of attachment style (anxiety and avoidance) revealed a positive correlation between the containment factors and anxiety $(0.28$, $0.32 p<0.001)$ and a negative correlation between the containment factors and avoidance $(-0.26,-0.25 p<0.001)$. These findings support the theoretical linkage between containment and attachment styles. Anxious attachment is inherently connected to the presence of a significant other, and avoidance relates to withdrawal and retreat after repeated disappointments with significant others as containment figures. A series of multivariate analyses were conducted to learn 
more about the relationship of each of the four factors (containment needs, containment fulfillment, anxiety and avoidance). In addition, we also controlled for socio-demographic variables such as age, gender and marital status. In our context, gender and marital status may have the strongest influence. Spending life with a significant other as opposed to being single might affect the experience of having one's containment needs fulfilled. With regard to gender, culturally, there is greater legitimacy for women than for men to share and express their needs to others. Previous research has demonstrated that women share more personal posts on Facebook than men [41] [42].

A multivariate analysis with the containment factors as dependent variables was significant $\left(F(5,255)=22.86, R^{2}=0.310, p<0.001\right)$ and suggested that the two dimensions of containment increase when anxiety is higher $(\beta=0.47, \mathrm{~B}=$ $0.40, \mathrm{t}=8.46, p<0.001)$ and avoidance is lower $(\beta=-0.39, \mathrm{~B}=-0.41, \mathrm{t}=-6.90$, $p<0.001$ ). The attachment dimensions contributed $26.1 \%$ to the explained variability in the containment factors.

We conducted additional multivariate analyses that separated containment needs and containment fulfillment. A regression model in which containment needs were the dependent variable was significant $\left(F(5,255)=13.69, R^{2}=0.21\right.$, $p<0.001)$, suggesting that containment needs are higher when the level of anxiety is high $(\beta=0.39, \mathrm{~B}=0.42, \mathrm{t}=6.52, p<0.001)$ and the level of avoidance is low $(\beta=-0.35, \mathrm{~B}=-0.47, \mathrm{t}=-5.87, p<0.001)$. The attachment dimensions contributed $19.2 \%$ to the explained variability.

A regression model in which the containment fulfillment factor was the dependent variable also proved significant $\left(F(5,255)=20.47, R^{2}=0.286, p<\right.$ $0.001)$, suggesting that when the level of anxiety is high $(\beta=0.45, \mathrm{~B}=0.40, \mathrm{t}=$ 7.99, $p<0.001)$ and the level of avoidance is low $(\beta=-0.35, \mathrm{~B}=-0.38, \mathrm{t}=-6.15$, $p<0.001)$, the experience of being contained or the sense that one's containment needs have been fulfilled is greater. The attachment factors contributed $23 \%$ to the explained variability.

A regression model in which anxiety was the dependent variable was significant $\left(F(5,255)=13.31, R^{2}=0.207, p<0.001\right)$. The results suggest that containment fulfillment is a predictor of anxiety $(\beta=0.29, \mathrm{~B}=0.33, \mathrm{t}=4.00, p<0.001)$, adding $13 \%$ to the explained variability. Containment needs were not significant.

A regression model in which avoidance was the dependent variable also proved significant $\left(F(5,255)=8.28, R^{2}=0.140, p<0.001\right)$. The results suggest that the need for containment $(\beta=-0.16, \mathrm{~B}=-0.12, \mathrm{t}=-2.17, p<0.05)$ predicts a lower score in avoidance, contributing $6.7 \%$ to the explained variability. This finding is supported by theory, because avoidance reflects a retreat and withdrawal from interactions with others. These analyses support the first hypothesis that containment is closely linked with attachment style. Nevertheless, the two concepts are not interchangeable.

To test H2, we conducted a hierarchical regression in step analysis. The results appear in Table 2. The regression model was significant, suggesting that a higher level of containment needs is positively related with posting personal statuses 
Table 2. Hierarchic regression analysis predicting using Facebook to post about a negative experience.

\begin{tabular}{crrr}
\hline Name of Factor & $\boldsymbol{t}$ & $\boldsymbol{B}$ & $\boldsymbol{\beta}$ \\
\hline Stage One: & & & \\
Gender $(\operatorname{Man}=1)$ & -0.62 & -0.12 & -0.04 \\
Age & -0.90 & -0.10 & -0.06 \\
Marital Status (Single = 1) & 2.51 & 0.45 & 0.16
\end{tabular}

Stage One Summation: $F(3,257)=2.17, R^{2}=0.013, p>0.05$

Stage Two:

Gender $(\operatorname{Man}=1)$
Age
Marital Status (Single $=1)$
Anxiety
Avoidance

$\begin{array}{ccc}-0.48 & -0.09 & -0.03 \\ -1.08 & -0.01 & -0.07 \\ 2.00^{*} & 0.37 & 0.13 \\ 3.09^{* *} & 0.21 & 0.20 \\ -1.31 & -0.11 & -0.09\end{array}$

Stage Two Summation: $F(5,255)=3.31, R^{2}=0.043, p<0.01$

$\begin{array}{cccc}\text { Stage Three: } & & & \\ \text { Gender }(\mathrm{Man}=1) & -0.02 & -0.01 & -0.01 \\ \text { Age } & -1.40 & -0.02 & -0.09 \\ \text { Marital Status (Single = 1) } & 2.41^{*} & 0.44 & 0.16 \\ \text { Need for Containment - Need for Sharing } & 3.08^{* *} & 0.22 & 0.24 \\ \text { Experience of Containment - Effect of Sharing } & 0.64 & 0.06 & 0.05 \\ \text { Anxiety } & 1.19 & 0.09 & 0.09 \\ \text { Avoidance } & 0.23 & 0.02 & 0.02\end{array}$

Stage Three Summation: $F(7,253)=4.77, R^{2}=0.092, p<0.001$

${ }^{*} p<0.05,{ }^{* *} p<0.01,{ }^{* * *} p<0.001$. Statistical abbreviations: $\alpha$ alpha, the probability of making a Type $1 \mathrm{er}-$ ror in hypothesis testing; $\beta$ beta, the probability of making a Type 2 error in hypothesis testing; F: F-ratio; $\mathrm{R}^{2}$ : coefficient of determination; $\mathrm{t}$ : $\mathrm{t}$-test value.

regarding negative events. This regression also implies that the need for containment outweighs attachment style and is dominant in producing statistical significance. The findings in previous studies regarding a similar relationship between anxiety and posting statuses about negative life events may reflect the element of containment needs that is intertwined in the anxious attachment style [36].

To examine $\mathrm{H} 3$ and $\mathrm{H} 4$ we conducted two hierarchal regression analyses. The regression model proved significant $\left(F(7,253)=5.45, R^{2}=0.131, p<0.001\right)$ and suggested that containment needs predict the speed of connecting to Facebook after the occurrence of a negative event $(\beta=0.18, \mathrm{~B}=0.19, \mathrm{t}=2.71, p<0.01)$. A multi-variant analysis with no hierarchy of steps proved non-significant, suggesting that attachment dimensions might have a blurring effect.

Another regression model revealed a similar picture regarding the speed of 
sharing on Facebook after the occurrence of a negative experience and was found to be significant $\left(F(7,204)=5.45, R^{2}=0.070, p<0.05\right)$. This significance suggests that containment needs predict the speed of posting a personal status on Facebook after the occurrence of a negative event $(\beta=0.19, \mathrm{~B}=0.21, \mathrm{t}=2.09$, $p<0.05)$. Table 3 presents the results of this hierarchal regression model.

A significant relationship emerged in which the fulfillment of containment needs and anxiety were predictors of a positive change in feeling after using Facebook. Containment needs, which predicted connecting to and writing on Facebook, might have contributed to seeking the fulfillment of these needs on Facebook and may have indirectly contributed to a positive change in feeling.

We used the same regression model to test H6. The results appear in Table 4 and suggest that the fulfillment of containment needs predicts the sense of being "seen" on Facebook, explaining $8.5 \%$ of the variance.

These final results imply that Facebook serves as a vessel for containment in that the need for containment and the anticipation of this need being fulfilled

Table 3. Hierarchic regression analysis predicting a positive change in feeling following the use of Facebook.

\begin{tabular}{|c|c|c|c|}
\hline Name of Factor & $T$ & $B$ & $\beta$ \\
\hline \multicolumn{4}{|l|}{ Stage One: } \\
\hline Gender $($ Man $=1)$ & 0.27 & 0.04 & 0.02 \\
\hline Age & 1.79 & 0.01 & 0.08 \\
\hline Marital Status (Single $=1$ ) & 1.79 & 027 & 0.12 \\
\hline \multicolumn{4}{|c|}{ Stage One Summation: $F(3,250)=2.10, R^{2}=0.025, p>0.05$} \\
\hline \multicolumn{4}{|l|}{ Stage Two: } \\
\hline Gender $($ Man $=1)$ & 0.50 & 0.08 & 0.15 \\
\hline Age & 1.11 & 0.01 & 0.07 \\
\hline Marital Status (Single $=1$ ) & 1.42 & 0.21 & 0.09 \\
\hline Anxiety & $4.83^{* * *}$ & 0.27 & 0.31 \\
\hline Avoidance & $-3.25^{\star *}$ & -0.22 & -0.21 \\
\hline \multicolumn{4}{|c|}{ Stage Two Summation: $F(5,248)=7.00, R^{2}=0.124, p<0.001$} \\
\hline \multicolumn{4}{|l|}{ Stage Three: } \\
\hline Gender $($ Man $=1)$ & 1.27 & 0.19 & 0.08 \\
\hline Age & 0.70 & 0.01 & 0.04 \\
\hline Marital Status (Single $=1$ ) & $2.13^{*}$ & 0.31 & 0.13 \\
\hline Need for Containment - Need for Sharing & 0.12 & 0.01 & 0.01 \\
\hline Experience of Containment - Effect of Sharing & $3.79^{* * *}$ & 0.29 & 0.30 \\
\hline Anxiety & $2.43^{*}$ & 0.17 & 0.14 \\
\hline Avoidance & -1.41 & -0.10 & -0.17 \\
\hline
\end{tabular}

${ }^{*} p<0.05,{ }^{* *} p<0.01,{ }^{* * *} p<0.001$ 
Table 4. Hierarchic regression analysis predicting the experience of the visibility of the self after posting on Facebook.

\begin{tabular}{cccc}
\hline Name of Factor & $t$ & $B$ & $\beta$ \\
Stage One: & & & \\
Gender $($ Man $=1)$ & 1.63 & 0.32 & 0.10 \\
Age & -0.23 & -0.01 & -0.02 \\
Marital Status (Single $=1)$ & $2.36^{*}$ & 0.43 & 0.15 \\
Stage One Summation: $F(3,256)=3.03, R^{2}=0.034, p>0.05$ & & & \\
Stage Two: & & & \\
Gender (Man $=1)$ & $2.50^{*}$ & 0.47 & 0.15 \\
Age & -0.67 & -0.01 & -0.04 \\
Marital Status (Single $=1$ ) & $2.95^{*}$ & 0.52 & 0.18 \\
Need for Containment - Need for Sharing & 1.68 & 0.12 & 0.13 \\
Experience of Containment - Effect of Sharing & $2.70^{* *}$ & 0.25 & 0.21 \\
Stage Two Summation: $F(5,255)=6.01, R^{2}=0.119, p<0.001$ & & & \\
\hline
\end{tabular}

${ }^{*} p<0.05,{ }^{* *} p<0.01,{ }^{* * *} p<0.001$

prompt people to connect to Facebook and post to it. Doing so leads to positive changes in their feelings and self-validation. The need for containment predicts the active use of Facebook such as writing posts and sharing, while the fulfillment of containment needs predicts positive improvements in one's feelings and sense of visibility. These results support our contention that considering the concept of containment in research on social networking may help explain who benefits emotionally from using Facebook and who does not, and provides explanations for the mixed findings regarding Facebook use.

\section{Discussion}

The purpose of this study was to examine the use of Facebook through a new lens-the psychoanalytical concept of containment-and tying it to two types of attachment styles that have proven to be significant in explaining the varying uses and experiences of using Facebook. This study represents a first attempt to bring the concept of containment needs out of the therapy room and into the field of research. Our findings support this theoretical move and the central hypotheses of this study. Containment needs are a significant predictor of using Facebook for personal posts, for writing about negative experiences, and for the speed of logging onto Facebook and sharing after a negative experience. The fulfillment of containment needs is a significant predictor of positive changes in one's feelings about oneself and one's visibility.

Using regression analyses to investigate the relationship between the concept of containment and attachment style reveals some new insights into the dynamics of these concepts with regard to Facebook use. Both anxiety and the need for containment are significant predictors of posting on Facebook. However, a hie- 
rarchical regression demonstrated that the need for containment is more significant than anxiety in predicting personal expression in writing on Facebook. This finding suggests that for people with greater containment needs and an anxious attachment style, the need for containment outweighs concerns about censoring one's negative feelings for fear of the critical responses of others.

Recent research has produced mixed results regarding the association between Facebook use and its psychological effects. Some studies associate Facebook postings with a reduction in feelings of loneliness and stress among women [14] [22] [43], while many other studies associate Facebook use with a negative effect on one's well-being, increasing feelings of envy and depression [17] [19].

The findings of the present study provide a possible interpretation and explanation of these mixed results by considering the role of containment needs and their fulfillment in the motivation to use Facebook, people's experiences on Facebook, and the psychological effects of using Facebook. We maintain that when containment needs are met, people experience a positive change in their feelings and a strengthening of their sense of self when using Facebook. In contrast, if these containment needs are not met, people experience negative psychological effects evident in a reduction in their well-being and sense of self-worth and an increase in depression. Previous studies that found positive effects of using Facebook usually dealt with people who posted on Facebook. In addition to expressing themselves, such individuals increase the likelihood of their containment needs being fulfilled by allowing others to respond to them. Negative feelings resulting from using Facebook have been associated with negative responses or lack of responses to one's postings, which suggest that the need for containment has not been met. Researchers who documented the negative psychological effects of using Facebook explained these results through social comparisons involving comparing oneself to the lives of others as depicted in Facebook posts [20]. Others explained the negative effects of using Facebook using the "like" functions [18]. These studies' findings deal with a more passive use of Facebook-reading the posts of others and responding with "like". In contrast, we focus on the active writing of posts that allows for containment needs to be filled through the positive, self-validating responses of others. In summary, this research suggests that containment needs predict Facebook use. In addition, the fulfillment of these needs may result in positive psychological effects, whereas the failure to meet these needs may result in negative psychological effects of using Facebook.

This study has several limitations that open up new avenues for future research. A major limitation stems from the fact that this is the first attempt to operationalize the clinical concept of containment. Further research is needed to validate and expand the containment needs questionnaire designed for this study, increase the sample size and add expert appraisal of the questionnaire's validity. A second limitation is related to the collection of the data based on a single questionnaire. Adding a longitude element and personal interviews would 
provide a richer data set and improve our interpretations.

Future research could also focus on the relationship between the items on the containment questionnaire and other parameters and questionnaires containing items related to well-being, self-image and self-estimation [44] [45]. Incorporating the containment needs questionnaire may produce a common theoretical and operational ground for these various concepts that are used in different studies. Another relevant development of the present study would be to investigate containment dynamics in other social networks such as Twitter, Instagram and Snapchat and instant messaging networks such as WhatsApp. Taking containment functions and the uses of social networking further, it would be interesting to examine to whom someone writes when posting on a social network-is there an actual or imaginary correspondent in mind when writing a personal post on Facebook?

\section{Conclusions}

Despite its limitations, this study contributes to the literature by providing a new lens through which to investigate the motivations for and gratifications of using Facebook and for explaining some of the mixed results on this topic in recent research.

Understanding negative effects of Facebook use as part of failure to meet containment needs might shed a light on why some Facebook users are more vulnerable than others.

\section{References}

[1] Smith, C. (2017) By the Numbers: 200+ Amazing Facebook Users Statistics. Retrieved February 14 from

http://expandedramblings.com/index.php/resource-how-many-people-use-the-topsocial-media/

[2] Fardouly, J. and Vartanian, L.R. (2015) Negative Comparisons about One's Appearance Mediate the Relationship between Facebook Usage and Body Image Concerns. Body Image, 12, 82-88. https://doi.org/10.1016/j.bodyim.2014.10.004

[3] Junco, R. (2015) Student Class Standing, Facebook Use, and Academic Performance. Journal of Applied Developmental Psychology, 36, 18-29.

https://doi.org/10.1016/j.appdev.2014.11.001

[4] Pai, P. and Arnott, D.C. (2013) User Adoption of Social Networking Sites: Eliciting Uses and Gratifications through a Means-End Approach [Electronic Version]. Computers in Human Behavior, 29, 1039-1053. Retrieved from http://www.journals.elsevier.com/computers-in-human-behavior/ https://doi.org/10.1016/j.chb.2012.06.025

[5] Papacharissi, Z. and Mendelson, A. (2011) 12 toward a New(er) Sociability: Uses, Gratifications and Social Capital on Facebook. In: Papathanassopoulos, S., Ed., $\mathrm{Me}$ dia Perspectives for the 21 st Century. Routledge, New York, 212-230.

[6] Park, N., Kee, K.F. and Valenzuela, S. (2009) Being Immersed in Social Networking Environment: Facebook Groups, Uses and Gratifications, and Social Outcomes [Electronic Version]. CyberPsychology \& Behavior, 12, 729-733. Retrieved from http://online.liebertpub.com/toc/cpb/11/1 
https://doi.org/10.1089/cpb.2009.0003

[7] Song, H., Zmyslinski-Seelig, A., Kim, J., Drent, A., Victor, A., Omori, K. and Allen, M. (2014) Does Facebook Make You Lonely? A Meta Analysis. Computers in Human Behavior, 36, 446-452. https://doi.org/10.1016/j.chb.2014.04.011

[8] Ellison, N.B., Steinfield, C. and Lampe, C. (2007) The Benefits of Facebook "Friends:" Social Capital and College Students' Use of Online Social Network Sites [Electronic Version]. Journal of Computer-Mediated Communication, 12, 1143-1168. Retrieved from https://doi.org/10.1111/j.1083-6101.2007.00367.x

[9] Smock, A.D., Ellison, N.B., Lampe, C. and Wohn, D.Y. (2011) Facebook as a Toolkit: A Uses and Gratification Approach to Unbundling Feature Use [Electronic Version]. Computers in Human Behavior, 27, 2322-2329. Retrieved from http://www.journals.elsevier.com/computers-in-human-behavior/ https://doi.org/10.1016/j.chb.2011.07.011

[10] Steinfield, C., Ellison, N.B. and Lampe, C. (2008) Social Capital, Self-Esteem, and Use of Online Social Network Sites: A Longitudinal Analysis. Journal of Applied Developmental Psychology, 29, 434-445. https://doi.org/10.1016/j.appdev.2008.07.002

[11] Joinson, A.N. (2008) Looking at, Looking up or Keeping up with People? Motives and Use of Facebook. In: Proceedings of the SIGCHI Conference on Human Factors in Computing Systems, ACM, New York, 1027-1036. https://doi.org/10.1145/1753326.1753613

[12] Sauter, T. (2014) What's on Your Mind? Writing on Facebook as a Tool for Self-Formation. New Media \& Society, 16, 823-839.

https://doi.org/10.1177/1461444813495160

[13] Burke, M., Marlow, C. and Lento, T. (2010) Social Network Activity and Social Well-Being. In: Proceedings of the SIGCHI Conference on Human Factors in Computing Systems, ACM, 1909-1912.

[14] Deters, F.G. and Mehl, M.R. (2012) Does Posting Facebook Status Updates Increase or Decrease Loneliness? An Online Social Networking Experiment. Social Psychological and Personality Science, 4, 579-586. https://doi.org/10.1177/1948550612469233

[15] Valkenburg, P.M. and Peter, J. (2007) Online Communication and Adolescent Well-Being: Testing the Stimulation versus the Displacement Hypothesis. Journal of Computer-Mediated Communication, 12, 1169-1182. https://doi.org/10.1111/j.1083-6101.2007.00368.x

[16] Appel, H., Gerlach, A.L. and Crusius, J. (2016) The Interplay between Facebook Use, Social Comparison, Envy and Depression. Current Opinions and Psychology, 9, 44-49.

[17] Shakya, H.B. and Christakis, N.A. (2017) Association of Facebook Use with Compromised Well-Being: A Longitudinal Study [Electronic Version]. American Journal of Epidemiology, 185, 203-211.

[18] Steers, M.L.N., Wickham, R.E. and Acitelli, L.K. (2014) Seeing Everyone Else's Highlight Reels: How Facebook Usage Is Linked to Depressive Symptoms. Journal of Social and Clinical Psychology, 33, 701-731. https://doi.org/10.1521/jscp.2014.33.8.701

[19] Tandoc, E.C., Ferrucci, P. and Duffy, M. (2015) Facebook Use, Envy, and Depression among College Students: Is Facebooking Depressing? Computers in Human Behavior, 43, 139-146.

[20] Verduyn, P., Lee, D.S., Park, J., Shablack, H., Orvell, A., Bayer, J., Ybarra, O., Jo- 
nides, J. and Kross, E. (2015) Passive Facebook Usage Undermines Affective Well-Being: Experimental and Longitudinal Evidence. Journal of Experimental Psychology: General, 144, 480. https://doi.org/10.1037/xge0000057

[21] Beaudry, R. (2015) Pew Research Says: Facebook and Twitter Reduce Stress in Women.

http://www.capitalberg.com/pew-research-says-facebook-twitter-reduce-stress-wo men/23515/

[22] Jain, A. (2015) Facebook, Twitter Can Lower Stress among Women [Study]. http://www.valuewalk.com/2015/01/facebook-twitter-lower-stress-women/

[23] Kannan, R. (2015) Facebook Either Improves or Worsens Mental Health: Research. http://www.thenewsreports.com/facebook-either-improves-worsens-mental-healthresearch/15703/ruby-kannan

[24] Bion, W.R. (1984) Second Thoughts: Selected Papers on Psycho-Analysis. Karnac, London.

[25] Bronsky, A. (n.d.) On the Development of Containment Ability. http://www.amibronsky.com/ArticleInner.aspx?iCatId=26\&iPageId=117

[26] Winnicott, D.W. (1971) Playing and Reality. Routledge, London.

[27] Ogden, T. (1992) The Matrix of the Mind: Object Relations and the Psychoanalytic Dialogue. Hebrew Edition 2005, Tolaat Sfarim, TLV, Karnac Books, New York.

[28] Perlov, M. (2011) Holding, Containment and in between Them. http://www.hebpsy.net/articles.asp?id=2655

[29] Blos, P. (1979) The Adolescent Passage: Developmental Issues. International Universities Press, New York.

[30] Stern, D.N. (1985) The Interpersonal World of the Infant: A View from Psychoanalysis and Developmental Psychology. Basic Books, New York.

[31] Sundén, J. (2003) Material Virtualities: Approaching Online Textual Embodiment. Peter Lang, New York.

[32] Turkle, S. (1995) Life on the Screen: Identity in the Age of the Internet. Simon \& Schuster, New York.

[33] Mikulincer, M. and Shaver, P.R. (2007) Attachment in Adulthood: Structure, Dynamics, and Change. Guilford Press, New York.

[34] Bowlby, J. (1969) Attachment and Loss 1: Attachment. Hogarth Press, London.

[35] Shaver, P.R. and Mikulincer, M. (2005) Attachment Theory and Research: Resurrection of the Psychodynamic Approach to Personality. Journal of Research in Personality, 39, 22-45.

[36] Oldmeadow, J.A., Quinn, S. and Kowert, R. (2013) Attachment Style, Social Skills, and Facebook Use amongst Adults. Computers in Human Behavior, 29, 1142-1149.

[37] Holmes, J. (1993) Attachment Theory: A Biological Basis for Psychotherapy? The British Journal of Psychiatry, 163, 430-438. https://doi.org/10.1192/bjp.163.4.430

[38] Brennan, K.A., Clark, C.L. and Shaver, P.R. (1998) Self-Report Measurement of Adult Attachment: An Integrative Overview. In: Jimpson, J.A. and Rholes, W.S., Eds., Attachment Theory and Close Relationships, The Guildford Press, New York, 46-76.

[39] Hart, J., Nailling, E., Bizer, G.Y. and Collins, C.K. (2015) Attachment Theory as a Framework for Explaining Engagement with Facebook. Personality and Individual Differences, 77, 33-40.

[40] Sandler, J. (1988) Projection, Identification, Projective Identification. Karnac Books, 
London.

[41] McAndrew, F.T. and Jeong, H.S. (2012) Who Does What on Facebook? Age, Sex, and Relationship Status as Predictors of Facebook Use. Computers in Human Behavior, 28, 2359-2365.

[42] Thompson, S.H. and Lougheed, E. (2012) Frazzled by Facebook? An Exploratory Study of Gender Differences in Social Metwork Communication among Undergraduate Men and Women. College Student Journal, 88-98.

[43] Bevan, J.L., Gomez, R. and Sparks, L. (2014) Disclosures about Important Life Events on Facebook: Relationships with Stress and Quality of Life. Computers in Human Behavior, 39, 246-253.

[44] Rosenberg, M. (1965) Society and the Adolescent Self-Image. Princeton University Press, Princeton. https://doi.org/10.1515/9781400876136

[45] Seiber, W.J., Groessl, E.J., David, K.M., Ganiats, T.G. and Kaplan, R.M. (2008) Quality of Well Being Self-Administered (QWB-SA) Scale. Health Services Research Center, University of California, San Diego. 